\title{
Pelvic floor neuropathy: a comparative study of diabetes mellitus and idiopathic faecal incontinence
}

\author{
J ROGERS, D M LEVY, M M HENRY, AND J J MISIEWICZ \\ From the Departments of Gastroenterology and Endocrinology, Central Middlesex Hospital, London
}

SUMmary Twenty one patients with diabetic peripheral neuropathy, 18 with idiopathic faecal incontinence and 11 normal controls were studied with techniques of mucosal electrosensitivity, rectal distension for the quantitative assessment of anorectal sensation, and manometric and electromyographic tests for the assessment of anorectal motor function. An asymptomatic sensorimotor deficit was found in the anal canal of patients with diabetic peripheral neuropathy. Mucosal electrosensitivity thresholds in the anal canal were significantly higher $(p<0.01 v$ controls $)$ and fibre density of the external anal sphincter significantly raised $(p<0.0001 v$ controls $)$. Anal manometry and pudendal nerve terminal motor latencies were similar to controls. In patients with idiopathic faecal incontinence the tests of sensory and motor function also showed a sensorimotor neuropathy; compared with controls, mucosal electrosensitivity thresholds were significantly higher $(p<0.002)$, anal canal resting and maximum squeeze pressures were significantly lower $(p<0.05$ and $p<0.002$ respectively), and pudendal nerve terminal motor latencies and fibre density of the external anal sphincter were significantly raised (both $p<0 \cdot 05$ ). Sensory thresholds to rectal distension were similar in all groups. Pelvic floor sensorimotor neuropathy in diabetic patients has several features in common with that of patients with idiopathic faecal incontinence but its functional significance remains uncertain.

Somatic and autonomic neuropathy are common complications of diabetes mellitus.' The somatic neuropathy is usually symmetrical, distal and sensory, and abnormalities of sensory nerve conduction in the legs have frequently been shown, even in newly diagnosed diabetics. ${ }^{2}$ Electrophysiological evidence of motor abnormalities usually occurs at a later stage of the disease. ${ }^{3}$

Diabetic neuropathy also has widespread effects in the gastrointestinal tract, largely because of involvement of autonomic nerves, ${ }^{4}$ and faecal incontinence is well recognised, often accompanying recurrent diarrhoea. ${ }^{5}$ An older report ${ }^{6}$ suggested an incidence as high as $18 \%$ in patients with clinical evidence of peripheral diabetic neuropathy, and more recently Schiller et $a l^{7}$ found that $20 \%$ of an unselected diabetic population had faecal incontinence. Its

Address for correspondence: Mr J Rogers, FRCS, Department of Gastroenterology, Central Middlesex Hospital. Acton Lane. Park Royal, London NW10 7NS.

Received for publication 17 November 1987 cause is uncertain. Patients with idiopathic faecal incontinence have been shown to have a combined somatic sensory and motor abnormality of the pelvic floor. ${ }^{8}$ The purpose of this study was to determine if subclinical abnormalities of anorectal sensorimotor nerve function occur in patients with diabetic peripheral neuropathy, and to compare the findings in these patients with age matched controls and patients with idiopathic faecal incontinence.

Methods

PATIENTS

The patients were studied in the left lateral position.

TESTS OF MOTOR FUNCTION

Anal manometry; functional anal canal length; resting and maximum squeeze pressures

These were measured using a closed water filled system consisting of a $4 \mathrm{~mm}$ diameter micro-balloon 
mounted on a polyethylene tube $2 \mathrm{~mm}$ in diameter connected to a pressure transducer (Statham Instruments Inc, Halto Rey, PR) and a pen recorder (Devices, London). The system was calibrated in $\mathrm{cm}$ water at ambient temperature and pressure. The balloon was lubricated with K-Y jelly (Johnson and Johnson Ltd, Slough) and gently inserted into the rectum; the pressure was continuously monitored as the balloon was removed in $1 \mathrm{~cm}$ stations. This allowed the resting pressure and functional length of the anal canal to be recorded. The balloon was reinserted into the anal canal to record the voluntary squeeze pressure.

\section{Pudendal nerve terminal motor latency}

This was measured using a specially constructed finger stall, " with stimulating electrodes mounted at the tip and recording electrodes mounted at the base connected to a standard electromyographic recording machine (MS6, Medelec Ltd, Woking, Surrey). The stimulator was inserted into the rectum and a supramaximal stimulus $(50 \mathrm{~V}, 0 \cdot 1 \mathrm{~ms})$ delivered to the pudendal nerve on each side. The action potential of the external anal sphincter was recorded by the base electrodes of the stimulator, allowing measurement of the latency of conduction."

\section{Single fibre electromyography}

Using a sterilised fine needle electrode with a recording surface of $25 \mu \mathrm{m}$ diameter (Medelec SF25533031) inserted into the external sphincter through the perianal skin, serial recordings of 20 different single muscle fibre electrical potentials were made. Analysis of the tracings allowed the calculation of the fibre density," "1" an index of motor unit clustering, a consequence of denervation and subsequent reinnervation.

\section{TESTS OF SENSORY FUNCTION}

\section{Mucosal electrosensitivity}

This was measured using a specially constructed probe comprising two platinum electrodes placed $1 \mathrm{~cm}$ apart near the tip of a 10FG polyvinyl catheter graduated in centimetres. Copper wires connected the electrodes to a constant current generator (Department of Medical Physics, BESA, UK), supplying $0 \cdot 1 \mathrm{~ms}$ square wave stimuli at a constant

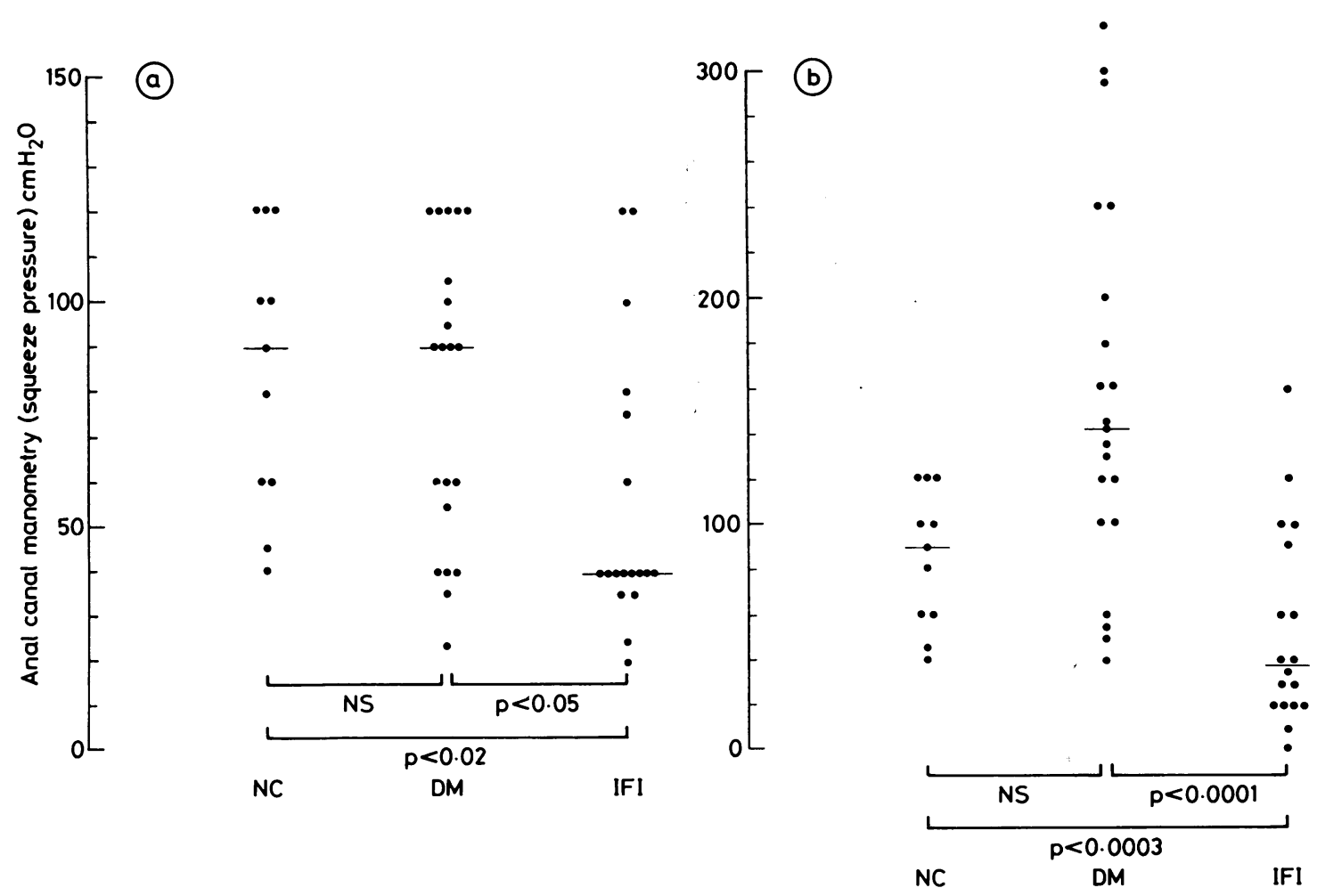

Fig. 1 Anal canal resting (a) and maximum squeeze (b) pressures ( $\mathrm{cm}$ water) in individual subjects. NC=normal controls, $D M=$ diabetics, $I F I=$ idiopathic faecal incontinence. Horizontal lines represent median values. 
rate of 5 pulses/second. The probe was lubricated with K-Y jelly and inserted to the midpoints of the upper, middle and lower thirds of the anal canal as determined by measurement of the functional anal canal length. The current across the electrodes was increased in steps of $0.1 \mathrm{~mA}$ until a threshold of sensation was reported by the patient, usually as a burning or tingling sensation. Three measurements of the threshold were made at each site and the lowest reading recorded.

\section{Rectal sensation}

This was tested using an adapted party balloon inserted into the rectum and inflated slowly in increments of $5 \mathrm{ml}$ with water at $37^{\circ} \mathrm{C}$. Records were made of the volumes required to give a constant sensation of fullness, the first sensation of desire to defecate and the maximum tolerated volume (usually associated with an irresistible urge to defecate).

Results are quoted as median with range of values in parentheses. Statistical analysis of the data was by Mann-Whitney U-test.

\section{PATIENTS}

Diabetic patients (21, four women, three multiparous, one nulliparous), mean age 55.3 years (range 36-72), mean time since diagnosis of diabetes $7 \cdot 7$ years (1-29). Eight were insulin dependent (type 1) diabetics; of the remainder four were treated with insulin, the others being on tablets or diet alone. All had neurophysiological evidence of peripheral neuropathy, with at least one of the following abnormalities: sural sensory action potential amplitude (needle electrodes) $<5 \mu \mathrm{V}$; common peroneal distal compound motor action potential amplitude $<4 \mathrm{mV}$; distal tibial compound motor action potential amplitude $<5 \mathrm{mV}$; and absent medial plantar sensory action potential. ${ }^{12}$ Nine had evidence of cardiac parasympathetic autonomic neuropathy, with heart rate variability on deep breathing $<10$ beats per minute. ${ }^{13}$ None had faecal incontinence, or history of local anorectal disorder, but three of the nine with autonomic neuropathy had symptoms of gastroenteropathy, with gastroparesis (episodic, otherwise unexplained, vomiting) and/or nocturnal diarrhoea. All had normal proctoscopic findings.

Patients with idiopathic faecal incontinence (18, eight women), mean age 54.1 years (25-83). No identifiable predisposing cause for incontinence could be found. All had normal neurological findings on clinical examination and normal sigmoidoscopic and proctoscopic findings. All were incontinent of solid stool. Three women were nulliparous, four multiparous and in four the last delivery preceded the onset of incontinence by at least 20 years.

Normal controls (11, four women), mean age $57 \cdot 9$
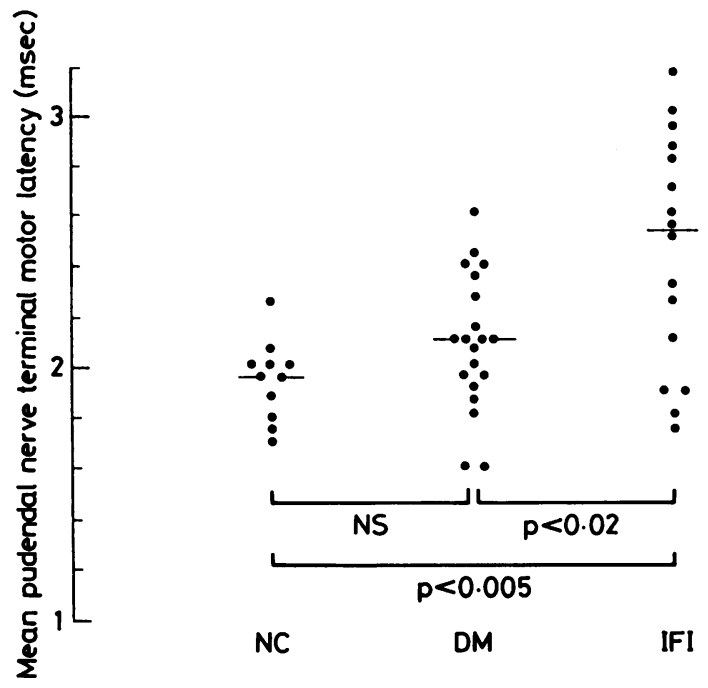

Fig. 2 Mean pudendal nerve terminal motor latencies (ms) in individual subjects. $N C=$ normal controls, $D M=$ diabetics, IFI=idiopathic faecal incontinence. Horizontal lines represent median values.

(25-75) years. These were volunteers with no history of diabetes or local anorectal disorder. All had normal sigmoidoscopic and proctoscopic findings.
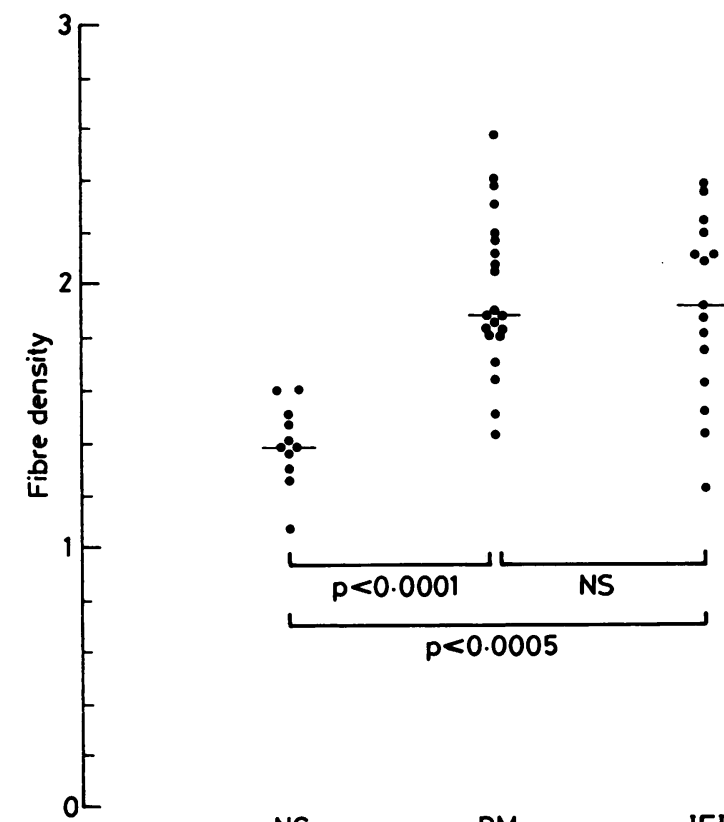

NC

DM

IFI

Fig. 3 Fibre densities in individual subjects. $N C=$ normal controls, DM=diabetics, IFI=idiopathic faecal incontinence. Horizontal bars represent median values. 


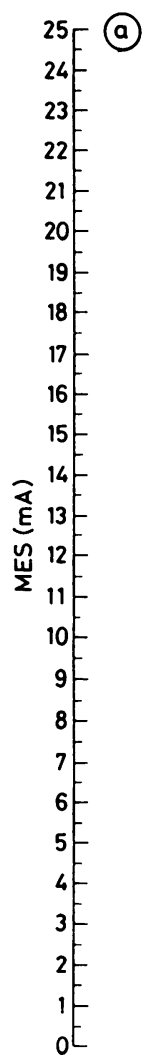

NC
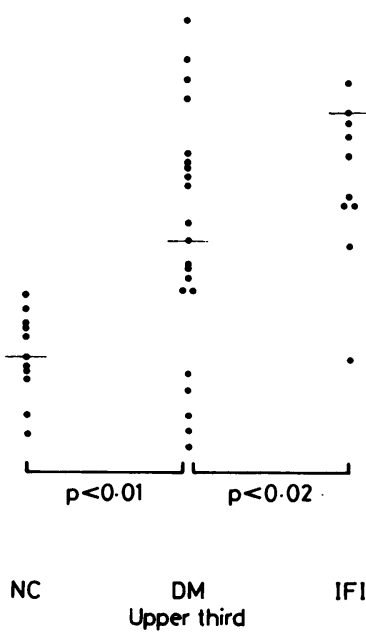

Fig. 4 Mucosal electrosensitivity $(m A)$ in individual subjects: (a) upper third of anal canal; (b) middle third of anal canal; (c) lower third of anal canal.

Two of the women were multiparous, one nulliparous.

Informed consent was obtained in all cases. The study was approved by the Brent Health Authority Ethical Committee.

\section{Results}

The results of the tests in the three groups are summarised in the Table. Observations in individual patients are shown in Figures 1-4.

TESTS OF MOTOR FUNCTION

The functional length of the anal canal of the diabetic patients was similar to that of controls $(4 \mathrm{~cm} \mathrm{(3-5)} v$ $4 \mathrm{~cm} \mathrm{(3-4))}$. This contrasted with the patients with idiopathic faecal incontinence, where the functional length of the anal canal was significantly shorter $(3 \mathrm{~cm}$ $(2-4) ; p<0 \cdot 0005 v$ diabetics and controls). In patients with idiopathic faecal incontinence, the tests of
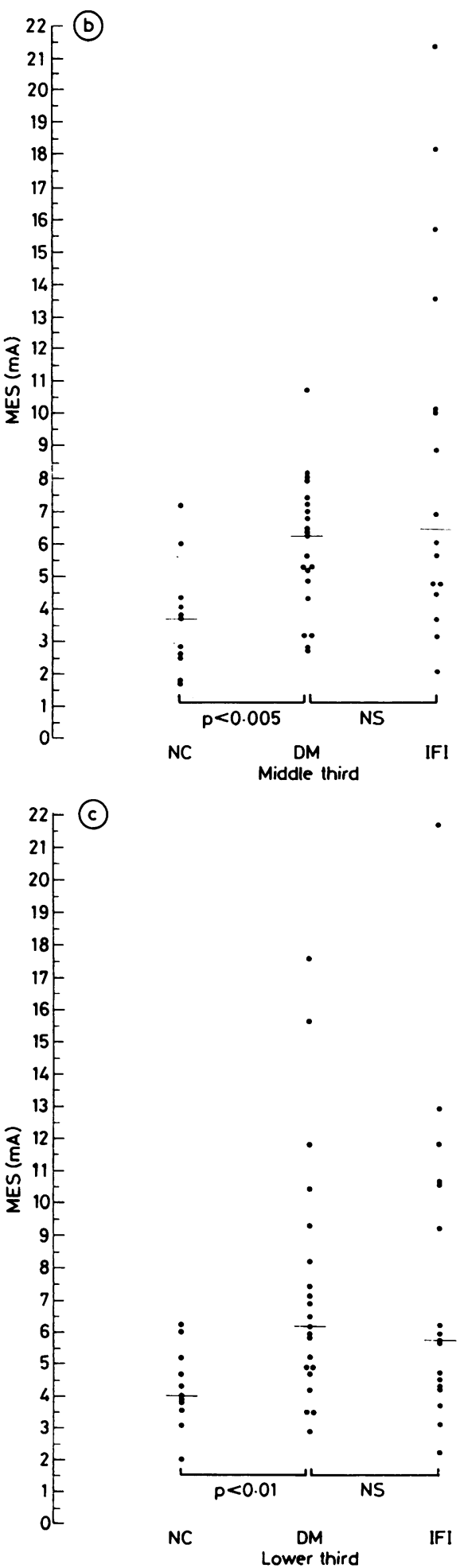
Table Results of motor and sensory testing in normal controls, diabetics and patients with idiopathic faecal incontinence, expressed as median (range)

\begin{tabular}{|c|c|c|c|}
\hline & Normal controls & Diabetics & Idiopathic faecal incontinence \\
\hline Anal canal length $(\mathrm{cm})$ & $4(3-5)$ & $4(3-4)$ & $3(2-4)^{*}$ \\
\hline Resting pressure (cm water) & $90(40-120)$ & $80(25-120) \ddagger$ & $40(20-120)^{*}$ \\
\hline Squeeze pressure (cm water) & $140(50-210)$ & $140(40-320)^{\dagger}$ & $40(0-160)^{*}$ \\
\hline Mean pudendal nerve terminal motor latencies (ms) & $1.95(1.70-2 \cdot 25)$ & $2 \cdot 10(1 \cdot 60-2 \cdot 45) \ddagger$ & $2 \cdot 50(1 \cdot 80-3 \cdot 15)^{*}$ \\
\hline Fibre density & $1 \cdot 38(1 \cdot 06-1 \cdot 60)$ & $1 \cdot 82(1 \cdot 42-2 \cdot 57)^{*}+$ & $2 \cdot 07(1 \cdot 21-2 \cdot 37)^{*}$ \\
\hline \multicolumn{4}{|l|}{ Mucosal electrosensitivity $(\mathrm{mA})$} \\
\hline upper third & $5 \cdot 3(3 \cdot 4-6 \cdot 9)$ & $8 \cdot 2(3 \cdot 1-13 \cdot 5)^{*}$ & $11 \cdot 2(5 \cdot 2-25 \cdot 0)^{*}$ \\
\hline middle third & $3 \cdot 7(1 \cdot 7-7 \cdot 2)$ & $6 \cdot 2(2 \cdot 7-10 \cdot 7)^{*}$ & $7 \cdot 0(2 \cdot 1-21 \cdot 4)^{*}$ \\
\hline lower third & $4 \cdot 0(2 \cdot 0-6 \cdot 2)$ & $6 \cdot 2(2 \cdot 9-17 \cdot 5)^{*}$ & $5 \cdot 7(8 \cdot 2-21 \cdot 6)^{*}$ \\
\hline \multicolumn{4}{|l|}{ Rectal distension ( $\mathrm{ml}$ water) } \\
\hline Fullness & $75(20-200)$ & $80(35-150)$ & $90(35-230)$ \\
\hline Urge volume & $120(40-250)$ & $120(40-200)$ & $120(70-250)$ \\
\hline Maximum tolerated volume & $150(70-235)$ & $170(50-350)$ & $150(95-250)$ \\
\hline
\end{tabular}

${ }^{*} \mathrm{p}<0 \cdot 01$ compared with controls; $\nmid \mathrm{p}<0 \cdot 01 ; \neq \mathrm{p}<0.05$ compared with idiopathic faecal incontinence.

motor function showed significant abnormalities; compared with control subjects, resting pressure and maximum squeeze pressure were lower $(\mathrm{p}<0.01$ and $\mathrm{p}<0.005$; Figures 1 (a) and 1 (b)); mean pudendal nerve terminal motor latencies was significantly increased ( $p<0.005$; Figure 2$)$; and fibre density was increased $(p<0 \cdot 0005 ;$ Figure 3$)$. In the diabetic patients resting pressure, maximum squeeze pressure and mean pudendal nerve terminal motor latencies were similar to controls (Figures 1 and 2). Fibre density in diabetics was significantly higher than normal subjects $(\mathrm{p}<0.0001)$ but similar to patients with idiopathic faecal incontinence (Figure 3 ).

\section{TESTS OF SENSORY FUNCTION}

The mucosal electrosensitivity thresholds to constant current stimulation in the anal canal were different in the three groups. Diabetic patients had a significant increase in median threshold at all levels in the anal canal compared with controls (upper third $p<0 \cdot 01$, middle third $p<0.005$, lower third $<0 \cdot 01$, Figure 4 ). Significant increases in mucosal electrosensitivity thresholds above control values were also recorded in idiopathic faecal incontinence (upper third $\mathrm{p}<0 \cdot 0001$, middle third $\mathrm{p}<0 \cdot 005$, lower third $<0.05$ ). The threshold in the upper third of the anal canal was significantly higher $(p<0.002)$ in idiopathic faecal incontinence, however, compared with diabetics (Figure 4). The results of rectal distension showed a wide range of values and were similar in all three groups.

\section{Discussion}

The results of this study show that an asymptomatic sensorimotor deficit exists in the anal canal of diabetic patients with peripheral neuropathy, and adds to the increasing neurophysiological evidence that neuropathy is a more common and widespread complication of diabetes ${ }^{14} 15$ than previously thought. Some of the findings in the pelvic floor are similar to those in patients with idiopathic faecal incontinence. Mucosal electrosensitivity showed a sensory deficit throughout the anal canal in patients with diabetes and idiopathic faecal incontinence. The deficit in the lower two-thirds of the canal was similar in both groups, but in the upper third of the anal canal the deficit in idiopathic faecal incontinence was significantly greater. The upper third of the anal canal is the sensory arm of the anal sampling reflex, ${ }^{16}$ and the greater deficit in idiopathic faecal incontinence may partly account for the difference in symptoms of the two groups. In contrast, the results of rectal distension studies were similar in all three groups. There are several possible explanations for the finding of a sensory deficit in the anal canal together with normal rectal sensation in diabetes and idiopathic faecal incontinence. First, it may be caused by the dual innervation of this region, the anal canal by somatic and the rectum by autonomic nerves $;{ }^{17}$ second, the absence of specialised nerve endings in the rectum; ${ }^{18}$ third, the location of the receptors which detect the stimulus in the pelvic floor or adjacent structures. ${ }^{19}$ These may account for the wide range of results obtained, compared with those for mucosal electrostimulation of the anal canal.

A motor deficit in diabetes and idiopathic faecal incontinence was shown by increased fibre density of the external anal sphincter in both conditions, but while anal canal manometry and pudendal nerve terminal motor latencies were normal in diabetics, they were respectively reduced and prolonged in idiopathic faecal incontinence. These findings may be accounted for by different neuropathological mecha- 
nisms in the two conditions. Neuropathy in idiopathic faecal incontinence is probably due to a combination of demyelination of the large fast conducting motor fibres and axonal degeneration secondary to direct or stretch injury of the pudendal nerves, reflected in the increased motor latency of the pudendal nerves and increased fibre density. Our results suggest that pelvic floor neuropathy in diabetes is primarily axonal in type, reflected by the raised fibre density. This is the generally held view of diabetic neuropathy, but is in contrast with a study by Thiele and Stalberg, ${ }^{21}$ using similar techniques applied to more distal nerves and muscle in diabetics where demyelination was thought to be the primary process, in keeping with their findings of normal fibre density and delayed motor nerve conduction. Demyelination is generally regarded as a late finding in diabetic nerve. ${ }^{3}$ From our results functional anorectal abnormalities in diabetes and idiopathic faecal incontinence would appear to be related more to prolonged pudendal nerve terminal motor latencies than increased fibre density and decreased anal canal sensitivity.

For incontinence to supervene, decreased anal canal pressure is required. This results from a decrease in the number of functioning motor units in the sphincter musculature. ${ }^{21}$ In our experience of sampling the motor unit fibre density, single muscle fibre potentials could be more readily found in the diabetics than in patients with idiopathic faecal incontinence, in whom the overall activity in the muscle was markedly reduced.

Although the current study offers no definitive insights into the pathogenesis of faecal incontinence in diabetes it suggests that while abnormal sensory and motor nerve function is common in the pelvic floor of patients with diabetic peripheral neuropathy, faecal incontinence may supervene only when the neuropathy has progressed to an advanced stage, probably in association with increased pudendal nerve terminal motor latencies and reduced sphincter tone. Alternatively, it may occur in the presence of adequate sphincter tone, when the diabetic pelvic floor is stressed by the onset of diarrhoea, probably as a result of reduced sensibility of the anal mucosa. This view will only be confirmed by a further study of a group of incontinent diabetic patients using the same techniques.

We are grateful to Dr S McHardy Young, Dr R R Abraham, and Dr R M Abraham for allowing us to study their patients and for helpful advice. Mr D Gee and Mr J Mears (WML-engineering) gave invaluable technical assistance. This work was supported by a Medical Research Council grant. DML holds a Fidia Research Fellowship.

\section{References}

1 Pirart J. Diabetes mellitus and its degenerative complications: a prospective study of 4400 patients observed between 1947 and 1973. Diabetes Care 1978; 1: 168-88.

2 Young RJ, Ewing DJ, Clarke BF. Nerve function and metabolic control in teenage diabetics. Diabetes 1983; 32: $142-7$.

3 Lamontagne A, Buchthal F. Electrophysiological studies in diabetic neuropathy. J Neurol Neurosurg Psychiatry 1970; 33: 442-52.

4 Scarpello JHB, Sladen GE. Diabetes and the gut. Gut 1978; 19: 1153-62.

5 Katz LA, Spiro HM. Gastrointestinal manifestations of diabetes. N Engl J Med 1966; 275: 1350-61.

6 Martin MM. Diabetic neuropathy: a clinical study of 150 cases. Brain 1958; 76: 594-624.

7 Schiller LR, Santa Ana CA, Schmulen C, et al. Pathogenesis of fecal incontinence in diabetes mellitus: evidence for internal-anal-sphincter dysfunction. N Engl J Med 1982; 307: 1666-71.

8 Rogers J, Henry MM, Misiewicz JJ. Combined sensory and motor deficit in primary neuropathic faecal incontinence. Gut 1988; 29: 5-9.

9 Kiff ES, Swash M. Slowed conduction in the pudendal nerves in idiopathic (neurogenic) faecal incontinence. Br J Surg 1984; 71: 614-6.

10 Neil ME, Swash M. Increased motor unit fibre density in the external anal sphincter muscle in anorectal incontinence: a single fibre EMG study. J Neurol Neurosurg Psychiatry 1980; 43: 343-7.

11 Stalberg E, Thiele B. Motor unit fibre density in the extensor digitorum communis muscle. J Neurol Neurosurg Psychiatry 1975; 38: 874-80.

12 Abraham RR, Abraham RM, Wynn V. Autonomic and electrophysiological studies in patients with signs or symptoms of diabetic neuropathy. Electroencephalogr Clin Neurophysiol 1986; 63: 223-30.

13 Ewing DJ, Clarke BF. Diagnosis and management of diabetic autonomic neuropathy. $B r$ Med J 1982; 285: 916-8.

14 Gupta PR, Dorfman LJ. Spinal somatosensory conduction in diabetes. Neurology $(N Y)$ 1981; 31: 841-5.

15 Levy DM, Abraham RR, Abraham RM. Small- and large-fibre involvement in early diabetic neuropathy: a study with the medial plantar response and sensory thresholds. Diabetes Care 1987; 10: 441-7.

16 Duthie HL, Bennett RC. The relation of sensation in the anal canal to the functional anal sphincter: a possible factor in anal incontinence. Gut 1963; 4: 179-82.

17 Last RJ. Anatomy: regional and applied. 6th ed. London: Churchill Livingstone, 1978.

18 Duthie HL, Cairns FW. Sensory nerve-endings and sensation in the anal region of man. Br J Surg 1960; 47: 585-94.

19 Lane RHS, Parks AG. Function of the anal sphincters following colo-anal anastomosis. Br J Surg 1977; 64: 596-9.

20 Thiele B, Stalberg E. Single fibre EMG findings in polyneuropathies of different aetiology. J Neurol Neurosurg Psychiatry 1975; 38: 881-7.

21 Henry MM, Swash M. In: Henry MM, Swash M, eds. Coloproctology and the pelvic floor: pathophysiology and management. London: Butterworths, 1985: 222-8. 